ENCYCLOPEDDIE Encyclopédie berbère

BERBERE

15 | 1995

15 | Daphnitae - Djado

\title{
Diana Veteranorum
}

(Aïn Zana)

G. Camps

\section{OpenEdition}

Journals

Édition électronique

URL : http://journals.openedition.org/encyclopedieberbere/2253

DOI : $10.4000 /$ encyclopedieberbere.2253

ISSN : 2262-7197

Éditeur

Peeters Publishers

Édition imprimée

Date de publication : 1 avril 1995

Pagination : 2295-2297

ISBN : 2-85744-808-2

ISSN : $1015-7344$

Référence électronique

G. Camps, «Diana Veteranorum », Encyclopédie berbère [En ligne], 15 | 1995, document D43, mis en ligne le 01 juin 2011, consulté le 24 septembre 2020. URL : http://journals.openedition.org/ encyclopedieberbere/2253; DOI : https://doi.org/10.4000/encyclopedieberbere.2253

Ce document a été généré automatiquement le 24 septembre 2020.

(c) Tous droits réservés 


\title{
Diana Veteranorum
}

\author{
(Aïn Zana)
}

\section{G. Camps}

1 Ville romaine de Numidie située à $90 \mathrm{~km}$ au sud-ouest de Constantine qui a conservé son nom au prix d'un léger glissement phonétique de $\mathrm{D}$ à $\mathrm{Z}$ à l'initiale. Ptolémée fait connaître une ville nommée Zana qui pourrait bien s'identifier à Diana et confirmerait l'hésitation entre ces deux sons chez les Africains de l'Antiquité; les exemples ne manquent pas : Madices/Mazices, Diaconus/Ziaconus.

2 L'agglomération fut d'abord une simple civitas fondée par des vétérans de la III Légion Augusta, vraisemblablement sous les Flaviens, en relation avec la construction, à Lambèse, du camp de Titus. La ville était déjà un municipe en 149 (A.E., 1930, n 40). Il semble qu'elle ait accédé à cette condition sous Trajan (97-117) car ses citoyens sont inscrits dans la tribu Papiria qui est celle de cet empereur. De nombreuses inscriptions mentionnent des magistratures et des sacerdoces divers : duumvir, édile, questeur, flamine, pontife, augure qui témoignent de la profondeur de la romanisation.

Les ruines de Diana ont livré une importante dédicace donnant le cursus honorum complet de M. Valerius Maximus qui fut légat de la III ${ }^{\mathrm{e}}$ Légion sous Commode après avoir participé, sur le Danube, aux guerres sarmates de Marc-Aurèle.

4 Le christianisme, qui a laissé tant d'édifices dans la Numidie centrale, semble avoir été implanté plus modestement à Diana Veteranorum qu'ailleurs. On ne connaît qu'un seul évêque de cette localité : Fidentius, donatiste sans compétiteur catholique, au Concile de Carfhage de 411. Encore n'est-on pas totalement assuré qu'il s'agisse bien de Diana veteranorum. S. Lancel, qui opte en faveur de cette attribution, signale toutefois l'existence d'une cité du même nom située, d'après l'Itinéraire d'Antonin, $(21,1)$ entre Hippo Regius (Annaba) et Tuniza (La Calle) et qui pourrait être la même cité que la Table de Peutinger (IV, 3) nomme Odiana et El Békri (p. 116), Zana. Il existait aussi en Maurétanie sitifienne un Castellum Dianense. La Prosopographie chrétienne du Bas-Empire se prononce sans hésitation en faveur de Diana veteranorum sans mentionner les autres Diana. Il est vrai que l'absence d'un compétiteur catholique s'explique mieux dans ce bastion donatiste qu'était la Numidie centrale que dans le voisinage d'Hippone. 
En 411, Diana ne possédait, semble-t-il, qu'une seule église dont on n'a pas retrouvé les traces. La seule basilique reconnue fut construite plus tard, à l'époque byzantine.

Diana veteranorum. Arc proche du forum élevé - en l'honneur de Marc Aurèle et Lucius Vérus (165) (Photo S. Gsell)

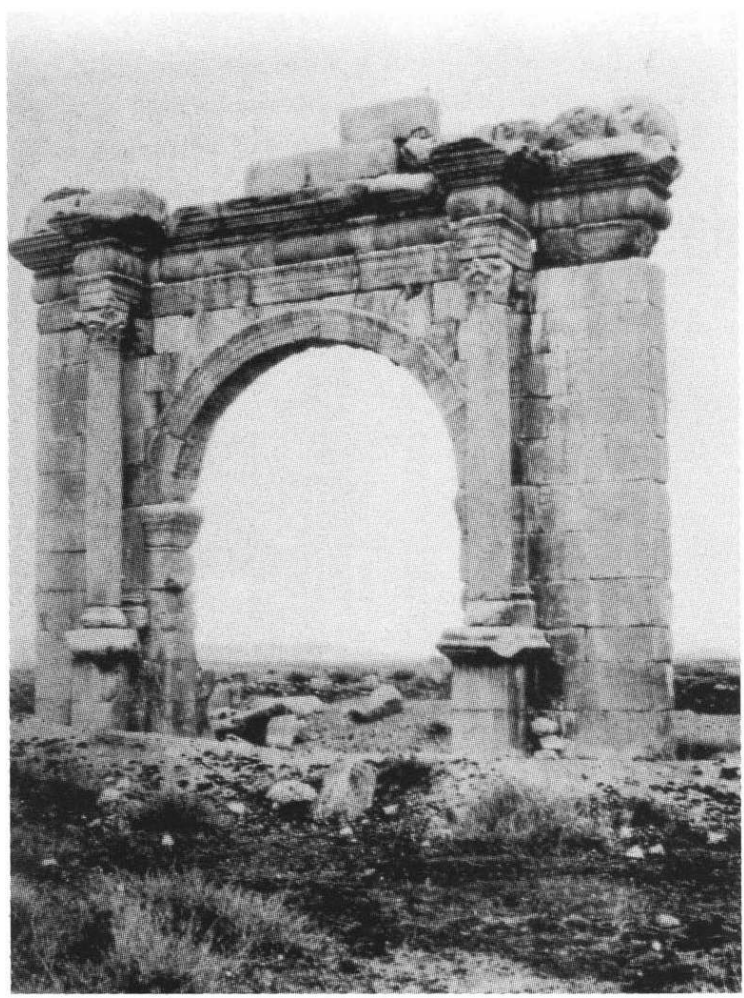

Les ruines de Diana couvrent une vaste surface et certains monuments ont encore une belle allure. On reconnaît dans le quartier sud-est un grand temple consacré, peut-être à Diane, mais le plus imposant est l'arc à trois portes qui date du règne de Macrin (213). Un autre arc, construit en 165, s'élevait à proximité du forum, vaste place dallée sur laquelle fut élevée l'église byzantine. Une croix monogrammatique en bas-relief incite à dater sa construction de la deuxième moitié du règne de Justinien au plus tôt. J. Christern voulait voir en ce bâtiment, long de $33 \mathrm{~m}$ sur une largeur de $17 \mathrm{~m}$, un « monument à auges », c'est-à-dire une hostellerie avec écurie. N. Duval s'éleva, avec raison, contre cette opinion.

6 Les ruines les plus apparentes sont, comme l'église, d'époque byzantine. La plus imposante est la forteresse qui s'élève à l'est du forum. C'est un bâtiment de plan très simple, un rectangle de $61 \mathrm{~m}$ de long et de $53 \mathrm{~m}$ de large muni d'une tour carrée saillante à chaque angle. La statue d'un lion trouvée à proximité pouvait en provenir à moins qu'elle n'ait appartenu à la décoration de l'un des imposants mausolées du voisinage. A la même époque ou plus tard, l'arc de Macrin servit d'appui à un fortin dont la face principale se confond avec ce monument. Les deux baies latérales de l'arc avaient été bouchées et la porte principale retrécie. Ce fortin mesurait 20,50 m sur $16,80 \mathrm{~m}$. 


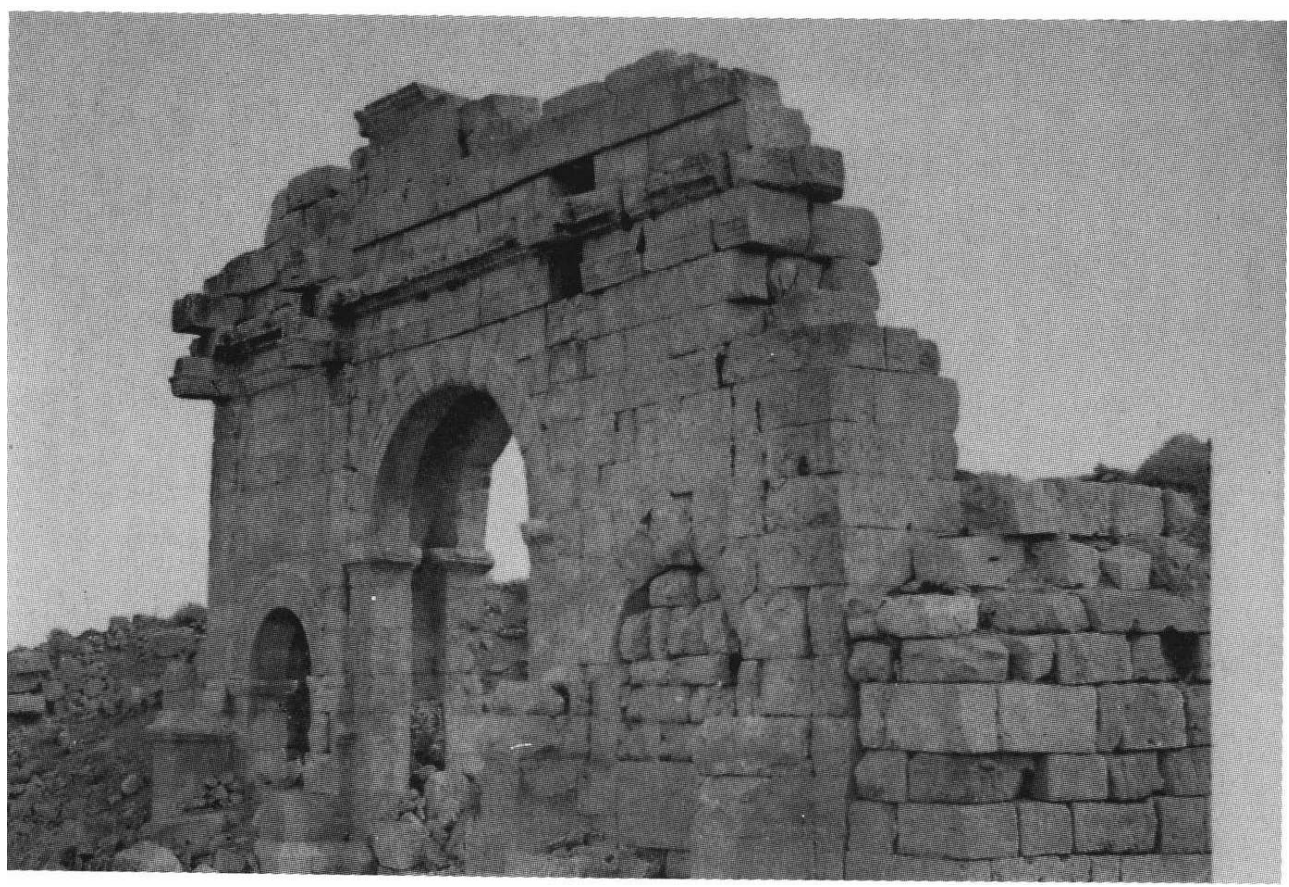

7 Diana resta un centre urbain d'une certaine importance, sans doute en raison de la mise en valeur de son territoire aujourd'hui parsemé de ruines de fermes et d'huileries. La ville survécut jusqu'au haut Moyen Age; il restait quelque souvenir de l'important nœud routier qu'elle avait été à l'époque romaine, lorsque des voies régulièrement entretenues la mettaient en relation avec trois capitales de province : Cirta, Lambèse et Sitifis.

\section{BIBLIOGRAPHIE}

GSELL S., Monuments antiques de l'Algérie, Paris, t. 1, p. 120, 127, 153, 154, 157, 164, 178, t. 2, p. 92, 339, $367,388$.

GSELL S., Atlas archéologique de l'Algérie, feuille 27, Batna, nº 62.

Anonyme, « Diana veteranorum, statue de lion », Libyca, Archéol. Epigraph., t. I, 1953, p. 284-285.

PFLAUM H.G, « Deux carrières équestres de Lambèse et de Zana », Libyca, Archéol. Epigraph., t. III, 1955, p. 124-154.

CHRISTERN J., Das Freichristliche Pilgerheiligtum von Tebessa, Weisbaden, 1976, p. 234 et 239-284.

LE GLAY M., « Diana veteranorum », Princeton Encyclopedia, 1979, p. 272.

LEPELLEY Cl., Les cités de l'Afrique romaine du Bas Empire, 2 vol. , Paris, 1979. 
GASCOU J., « La politique municipale de l'Empire romain I, de la mort d'Auguste au début du III siècle » « II, Après la mort de Septime sévère », Aufstieg und Niedergang der romischen Welt, 10, 2, p. 136-320.

LANCEL S., Actes de la conférence de Carthage en 411, t. IV, Paris, 1991, p. 1370-1371.

GUI I, DUVAL N., CAILlET J.-P., Basiliques chrétiennes d'Afrique du Nord, I, Inventaire de l'Algérie, Paris, 1992, p. 156-158.

INDEX

Mots-clés : Algérie, Antiquité, Numides, Ville 